\title{
Are symptoms of restless legs syndrome generated in the periphery of the nervous system or are they born centrally?
}

The clinical case "Restlessness in right upper limb as sole presentation of restless legs syndrome ${ }^{\prime \prime[1]}$ presented by Gupta and colleaguesin this volumeandissue of the Journal of Neurosciences in Rural Practicerefers us to an as-yet debated issue on the pathophysiologyof restless legs syndrome (RLS): Are the neuroanatomical sites of generation of the unpleasant, annoyingsymptoms of the disease peripheral or central?

Karl A. Ekbom, who initiated the studies (1945) on $\operatorname{RLS}^{[2,3]}$ was also one of the first researchers to describe RLS in amputees (1961). In his paper, ${ }^{[4]}$ through a clear and logical reasoning, he hypothesized that the symptoms were generated in the periphery of the nervous system. The question is still unansweredfor most modern researchers of RLS. ${ }^{[5]}$ However, many insights derived from clinical observations of RLS also influence us to assume that RLS symptoms are generated in the periphery: 1) In amputees, frequently, symptoms are 'phantom', that is, felt as if generated from the leg that is missing, 2) if RLS patients move or stretch their legs they experience some relief (seems logical because if the symptoms were central, therestlessness would not cease with movement), 3) massagingthe affected limb or applying cold pads lead frequently to ameliorationof symptoms (very little probability that such commonplacenonpharmacologicalmeasures would alleviate the symptoms if they were generated centrally), and 4) in some subjects submitted to total knee arthroplasty, RLS may ensue only after the surgery and only in the knee articulation with the prosthesis device. ${ }^{[6,7]}$ Also, the mechanisms underpinning RLS pathophysiology are considered unknown; however,

\begin{tabular}{|l|l|}
\hline \multicolumn{2}{|c|}{ Access this article online } \\
\hline Quick Response Code: & Website: \\
\hline & www.ruralneuropractice.com \\
\cline { 2 - 2 } & \\
\hline & \\
\hline
\end{tabular}

recently we theorized that the RLS symptoms are secondary to an imbalance between two forces, the hypothalamus-pituitary-thyroid axis and the dopaminergic system, ${ }^{[8]}$ a hypothesis based on sufficient circumstantial evidence.

RLS may be primary or secondary to a number of conditions including peripheral neuropathies. Gupta and colleagues describe a rather interesting case of a woman who initiated her restless symptoms in the right upper limb. However, the assumption that their case is one of primary RLSmust be cautiouslytreated. RLS is a disease of deranged sensibility, and not of motor impairment. So, efforts to search for peripheral neural impairment might be misleading, as for instance when one studies a possible case of thoracic outlet syndromeclinically, and when only sensitive symptomatology is being observed. One important principle of the physiologyof the somatosensory system (principle of the labeled lines) is that when a nerve fiber isstimulated at any point on its path to the sensory cortex, the stimulus evokes symptoms exactly as if they were coming from the territory nourished by the nerve fiber ${ }^{[9]}$ As the patient in this case has a cervical rib, only a clinical study might not be sufficient for a precise diagnosis of the case. Is it a case of primary RLS or a secondary one? Would not be possible that the neural fibers, coming from the cutaneous territory where the patient feels the symptoms, were stimulated on their passage through the cervical rib region? Ancillary studiessuch as electromyography and image studies perhaps could have helped toward a more precise diagnosis: Was the caseof Gupta and colleagues' a primary or secondary one? Another important point to remember is that their patient does not have any close relative suffering from RLS, which makes the diagnosis of a primary RLS a bit more difficult.

José Carlos Pereira

Department of Pediatrics, Jundiaí Medical School, São Paulo, Brazil 
Address for correspondence:

Dr. José Carlos Pereira,

Rua Isaí Leiner 54, Jundiaí, São Paulo, Brazil. CEP: 13201 - 854.

E-mail: joscarlospereirajr@gmail.com

\section{References}

1. Gupta R, Lahan V, Goel D. Restlessness in right upper limb as sole presentation of restless legs syndrome. J Neurosci Rural Pract 2013;4:77-9

2. Ekbom KA. Restless legs: A clinical study. Acta Med Scand 1945;158:1-122.

3. Ekbom K, Ulfberg J. Restless legs syndrome. J Intern Med 2009;266:419-31.

4. Ekbom KA. Restless legs in amputees. Acta Med Scand 1961;169:419-21.

5. Hening WA, Allen RP, Walters AS, Chokroverty S. Motor Functions and Dysfunctions of Sleep. In: Chokroverty S, editor. Sleep Disorders Medicine. Philadelphia: Saunders; 2009. p. 397-435.

6. Pereira JC Jr., Alves RC. Restless legs syndrome: Is it a functional peripheral neuropathy? Presented as the poster W-L099 at the WASM/ CSS Congress. Quebec: Canada: 2011.

7. Pereira JC Jr, Silva Neto JL, Pradella-Hallinan M. Restless legs syndrome in subjects with knee prosthesis: Evidence that symptoms are generated in the periphery. Clinics (Sao Paulo) 2011;66:1955-9.

8. Pereira JC Jr, Pradella-Hallinan M, Lins Pessoa H. Imbalance between thyroid hormones and the dopaminergic system might be central to the pathophysiology restless legs syndrome: A hypothesis. Clinics (Sao Paulo) 2010;65:548-54.

9. Pereira JC Jr, Alves RC. The labelled-lines principle of the somatosensory physiology might explain the phantom limb phenomenon. Med Hypotheses 2011;77:853-6.

How to cite this article: Pereira JC. Are symptoms of restless legs syndrome generated in the periphery of the nervous system or are they born centrally?. J Neurosci Rural Pract 2013;4:1-2.

Source of Support: Nil. Conflict of Interest: None declared.

\section{“QUICK RESPONSE CODE” LINK FOR FULL TEXT ARTICLES}

The journal issue has a unique new feature for reaching to the journal's website without typing a single letter. Each article on its first page has a "Quick Response Code". Using any mobile or other hand-held device with camera and GPRS/other internet source, one can reach to the full text of that particular article on the journal's website. Start a QR-code reading software (see list of free applications from http://tinyurl.com/yzlh2tc) and point the camera to the QR-code printed in the journal. It will automatically take you to the HTML full text of that article. One can also use a desktop or laptop with web camera for similar functionality. See http://tinyurl.com/2bw7fn3 or http://tinyurl.com/3ysr3me for the free applications. 